\title{
ATAXIA EPISÓDICA NÃO FAMILIAR POSSIVELMENTE ASSOCIADA COM O USO DE NICOTINA
}

\author{
RELATO DE CASO
}

ANDERSONKUNTZ GRZESIUK*

\begin{abstract}
RESUMO - O autor relata um caso clínico de ataxia episódica não familiar responsiva a acetazolamida, semelhante clinicamente a ataxia episódica tipo 2 (EA-2), no qual a nicotina pode representar ser um possível fator na gênese dos episódios atáxicos.
\end{abstract}

PALAVRAS-CHAVE: ataxia episódica, acetazolamida, nicotina.

\section{Non-familial episodic ataxia possibly associated with the use of nicotine: case report}

ABSTRACT - The author reports a case of non-familial episodic ataxia responsive to acetazolamide, clinically similar to episodic ataxia type 2 (EA-2), in which nicotine is a possible factor in the origin of the ataxic episodes.

KEY WORDS: episodic ataxia, acetazolamide, nicotine.

As ataxias episódicas são desordens familiares raras, de penetrância autossômica dominante, classificadas clínica e geneticamente em duas formas: ataxia episódica tipo 1 (EA-1) e ataxia episódica tipo 2 (EA-2) ${ }^{1,2}$. A ataxia episódica tipo 1 caracteriza-se por episódios rápidos de ataxia, com duração de segundos a poucos minutos, sendo desencadeada principalmente por sustos ou exercícios físicos. Observa-se a presença de mioquimias inter-ictais, geralmente ao redor dos olhos e/ou mãos. A causa desta desordem está relacionada a mutações no gene dos canais de potássio, KCNA1, localizado no cromossomo 12p. A ataxia episódica tipo 2 caracteriza-se clinicamente por episódios atáxicos que duram de horas a até mais de um dia, precipitados geralmente por stress emocional, fadiga, exercícios físicos e algumas vezes pelo uso de álcool.

Geralmente há a associação de vertigem, cefaléia e náuseas. Caracteriza-se por apresentar boa resposta ao uso de acetazolamida. Vahedi e cols. ${ }^{3}$ localizaram no cromossomo $19 \mathrm{p}$ a desordem responsável por esta forma de ataxia episódica, também relacionada aos canais de potássio. Contudo esta forma de ataxia familiar também está relacionada a mutações no gene dos canais de cálcio CACNA1 $\mathrm{A}^{4}$. Esta forma de ataxia está ligada a mesma região do cromossomo 19 que é responsável pela enxaqueca hemiplégica familiar e pelo CADASIL ${ }^{4}$.

Em 1982, Braham e cols..$^{5}$ descreveram um caso de ataxia episódica responsiva à acetazolamida em um jovem de 19 anos, sem história familiar de ataxia periódica. Em 1985, Verlooy e Velis ${ }^{6}$ descreveram outro caso semelhante, em um homem de 44 anos, sem história familiar, cujos episódios atáxicos eram desencadeados por stress físico ou emocional, e que

*Neurologista, Hospital Santa Rosa, Cuiabá, Brasil. Aceite: 8-maio-2000.

Dr. Anderson Kuntz Grzesiuk - Rua Custódio de Mello 630/103 - 78030-340 Cuiabá MT - Brasil. E-mail: neuroakg@zaz.com.br 
apresentou boa resposta ao uso de acetazolamida. Yue e col. descreveram recentemente um caso de ataxia episódica não familiar responsiva a acetazolamida, onde foram encontradas mutações no gene dos canais de cálcio CACNA1 $\mathrm{A}^{4}$.

Descreve-se neste artigo um caso de ataxia episódica não familiar responsiva à acetazolamida, cujos episódios atáxicos podem estar relacionados em parte ao uso de nicotina.

\section{CASO}

RLSC, mulher, branca, 34 anos, natural do estado do Paraná , residente em Mato Grosso. Em maio de 1999, foi internada no Hospital Santa Rosa, com quadro de vertigem, nistagmo, náuseas e vômitos, sendo tratada clinicamente como um caso de "labirintite" por um clínico geral, com melhora do quadro em $48 \mathrm{~h}$, recebendo alta hospitalar assintomática. Em novembro de 1999, apresentou novo quadro, de início súbito, de vertigem rotatória, náuseas e vômitos, cefaléia pulsátil, apresentando ao exame neurológico, nistagmo vertical, marcha atáxica, incoordenação bilateral e disartria, estando normal o restante do exame neurológico. Iniciou-se investigação do caso, inicialmente com uma ressonância magnética de crânio, que foi normal. A análise de rotina do líquor foi normal, sendo encaminhado material para eletroforese de proteínas liquóricas, cujo resultado demorou 30 dias. A paciente apresentou melhora do quadro em $48 \mathrm{hs,} \mathrm{recebendo} \mathrm{alta} \mathrm{assintomática,} \mathrm{para} \mathrm{investigação} \mathrm{ambulatorial.} \mathrm{No}$ décimo dia após a alta hospitalar, apresentou novo quadro, com as mesmas características, sendo realizada pulsoterapia com metilprednisolona na dose de 1,0 grama EV, por 5 dias, optando-se por não manter prednisona VO. Houve melhora dos sintomas em $72 \mathrm{hs}$. A eletroforese de proteínas do LCR resultou normal, afastando-se a possibilidade de esclerose múltipla. Aproximadamente 9 dias após, em uso de prednisona $40 \mathrm{mg} \mathrm{VO}$, apresentou novo quadro, com as mesmas características, sendo hospitalizada para investigação e tratamento sintomático, havendo regressão do quadro com uso de metilprednisolona por 3 dias, seguido de prednisona $\mathrm{VO}$,em doses decrescentes. Aventou-se a hipótese de quadro vasculítico, tendo-se realizado dosagem de FAN (Hep 1 e 2), anti-HIV, anticardiolipina, anticoagulante lúpico, anti-fosfolipídeo, VDRL, P-ANCA, C-ANCA, coagulograma e FTA-ABS, resultando todos normais. A angiografia cerebral foi normal. Em dezembro de 1999, a paciente apresentou novo quadro, com as mesmas características, quando foi iniciada investigação para a possibilidade de tratar-se de síndrome paraneoplásica. Ultrassonografia de abdômen total, com atenção aos ovários, mamografia , tomografia computadorizada de tórax, e dosagem sérica de T3, T4 e TSH, foram normais. Realizou-se a dosagem sérica dos seguintes aminoácidos: triptofano= $0,53 \mathrm{mg} / \mathrm{dl}$ (valor normal, $\mathrm{VN}=0,51-1,49 \mathrm{mg} / \mathrm{dl}) ;$ fenilalanina $=1,69 \mathrm{mg} / \mathrm{dl}(\mathrm{VN}=0,8-2,0 \mathrm{mg} / \mathrm{dl}) ;$ metionina:0,88 mg/ dl (VN=0,09-0,60 mg/dl); leucina: 0,95 mg/dl (VN=0,98-2,29 mg/dl); tirosina: 2,24 mg/dl (VN=0,8-4,9 mg/dl); valina: $1,88 \mathrm{mg} / \mathrm{dl}(\mathrm{VN}=1,65-3,71 \mathrm{mg} / \mathrm{dl})$; isoleucina: $0,74 \mathrm{mg} / \mathrm{dl}(\mathrm{VN}=0,48-1,28 \mathrm{mg} / \mathrm{dl})$. Considerou-se a hipótese clínica de ataxia cerebelar episódica, sendo descontinuado o uso do corticóide, e introduzido-se acetazolamida, na dose de $250 \mathrm{mg}$ por dia VO, havendo melhora gradativa do quadro.

A paciente em questão é portadora de depressão de longa data, obesidade, distúrbios de auto-estima e tabagista , utilizando em média 20 cigarros ao dia. Nega uso de bebidas alcoólicas. Não há relato de casos semelhantes na família. Observou-se que nos dias que precediam cada um dos episódios atáxicos, a mesma havia apresentado problemas familiares, piorando seu quadro depressivo, aumentando concomitantemente o consumo de cigarros, havendo ocasiões de utilizar até 50 cigarros em um dia, sendo que durante as internações ela não fumou por até uma semana.

Atualmente a paciente encontra-se em uso de acetazolamida $250 \mathrm{mg} / \mathrm{dia}$, flunarizina $10 \mathrm{mg} / \mathrm{dia}$ e sertralina $50 \mathrm{mg} / \mathrm{dia}$. Ela conseguiu reduzir o consumo de cigarros para até 3 ao dia. Recentemente suspendeu o uso da acetazolamida, apresentando episódio atáxico após 3 dias, havendo regressão dos sintomas com a reintrodução da medicação.

\section{DISCUSSÃO}

As ataxias cerebelares têm sido extensamente pesquisadas, no intuito de conhecer-se o seu mecanismo de desencadeamento, e desta forma poderem ser melhor compreendidas e tratadas de forma racional. Dentre os sistemas neurotransmissores conhecidos envolvidos no funcionamento do cerebelo, o sistema serotoninérgico aparece como um dos sistemas de maior influência, como demonstrado por Lou e col. em estudo utilizando buspirona, um agonista serotoninérgico, no qual observou-se uma melhora nos sintomas apresentados pelos pacientes atáxicos ${ }^{7}$. Esta observação foi demonstrada também por Friedman com o uso da buspirona em pacientes com doença de Joseph-Machado ${ }^{8}$, assim como por Rohr e col. com o uso de citalopram em pacientes com ataxia de Friedreich'. 
A serotonina (5-HT) é derivada do aminoácido triptofano, sendo formada após a ação sequencial das enzimas triptofano hidroxilase e 5-HTP decarboxilase sobre este aminoácido. A formação da serotonina encontra-se limitada pela disponibilidade do triptofano no liquido extracelular aos neurônios. A obtenção do triptofano pelo cérebro é feita através do sangue, e este o obtém da dieta, ocorrendo relação direta entre a deficiência do triptofano na dieta e a depleção da serotonina no cérebro ${ }^{10}$. A maioria das vias da serotonina origina-se nos neurônios da região do núcleo dorsal da rafe, enviando terminações serotoninérgicas para as células de Purkinje e camada granular do cerebelo. Os receptores da serotonina no cérebro estão divididos em 7 subtipos: 5-HT1A, 5-HT1B, 5-HT1C, 5-HT1D, 5-HT2A, 5-HT2B e 5-HT3, sendo que os subtipos 5-HT1A são os receptores serotoninérgicos do cerebelo ${ }^{7}$. Na maioria das áreas do sistema nervoso central, a serotonina tem ação inibitória, mediada pelos receptores 5-HT1A, causando aumento na condutância do potássio, o que leva a hiperpolarização da membrana celular ${ }^{11}$.

Dentre os fatores que estão relacionados ao desencadeamento de quadro atáxico em pacientes portadores de ataxia episódica familiar (EA-1 e EA-2), o stress emocional ocupa um papel importante ${ }^{1,2}$, possivelmente relacionado a alterações no sistema serotoninérgico. Os distúrbios no mecanismo da serotonina estão também ligados à gênese dos quadros depressivos, e portanto uma relação comum é possivel entre os quadros de ataxia e alterações do humor.

$\mathrm{Na}$ paciente relatada, o quadro depressivo é evidente, tendo-se observado piora do fator depressivo em todos os episódios atáxicos, contudo chamou-nos a atenção uma possível influência da nicotina do cigarro, pois era evidente o grande aumento do consumo de cigarros precedendo os episódios atáxicos. Johnsen e Miller ${ }^{12}$ relataram piora nos sintomas de ataxia em um paciente com atrofia de múltiplos sistemas que fazia uso de cigarros, fato este também relatado por Houi e col. em pacientes com degeneração espinocerebelar ${ }^{13}$. Benwell e Balfour ${ }^{14}$ estudando os efeitos da administração de nicotina em cérebros de ratos, concluiram que a administração crônica de nicotina pode levar a uma baixa dos níveis de serotonina no hipocampo, resultando da redução da biossíntese da serotonina, fato que ocorre devido a uma redução na atividade do sistema carreador do Ltriptofano ${ }^{14}$. Takada e col $^{15}$, estudando a influência do stress induzido a ratos, com e sem a administração concomitante de nicotina, concluiram que o fator stress associado a administração de nicotina levou a redução nos níveis plasmáticos de triptofano. Em outro trabalho, estes autores observaram que a nicotina reduz o incremento stress-induzido dos níveis de serotonina no hipocampo e no cerebelo de ratos $^{16}$.

O atual enfoque em relação as causas das ataxias episódicas está baseado nas alterações/ mutações dos genes responsáveis pela formação dos canais iônicos, principalmente os canais de potássio (EA-1 e EA-2) e cálcio (EA-2) ${ }^{1,2}$. Além dos diferentes cromossomos aos quais estão ligadas, as ataxias episódicas diferenciam-se clinicamente pela responsividade ao uso da acetazolamida, marcante na ataxia episódica tipo $2^{1,2}$. O efeito benéfico desta droga em pacientes com EA-2 foi relatado por Griggs e col. ${ }^{17} \mathrm{em}$ um paciente que havia sido erroneamente diagnosticado como portador de paralisia periódica, e que apresentou dramática resposta ao uso de acetazolamida. Presume-se que a ação da acetazolamida seja estabilizar os canais iônicos anormais, através de mudanças no pH extracelular ${ }^{18}$. A redução no $\mathrm{pH}$ (aumentando o número de prótons livres) inibe fortemente a permeabilidade iônica através dos canais de cálcio abertos, assim como reduz a abertura destes canais. Desta forma, aumentando a concentração extracelular de prótons no cerebelo, esta droga estabiliza os canais iônicos mutantes que não conseguem inativar-se corretamente ${ }^{4}$.

Em um estudo publicado em 1998, Yue e col. demonstraram que alterações nos canais iônicos CACNA1A são os responsáveis pelo quadro de ataxia episódica não familiar em um caso, fator este já referido anteriormente em pacientes com história familiar, classificando-o assim como uma nova mutação ${ }^{4}$.

Baseado nas evidências de alterações no funcionamento do sistema serotoninérgico na gênese das ataxias cerebelares, e considerando as evidências de alterações causadas pela nicotina sobre o ciclo do triptofano, precursor da serotonina, acredito que o presente caso de ataxia episódica não 
familiar apresente semelhanças clínicas com o caso descrito por Yue e col, sendo que a nicotina consumida pela paciente na forma de cigarro, associada à depressão, representaria fator associativo no desencadeamento dos episódios atáxicos. A nicotina possivelmente agiria como redutor na disponibilidade do triptofano. Esta influência da nicotina, associada ao estabelecido distúrbio do sistema serotoninérgico relacionado à depressão, acarretaria redução na formação e disponibilidade da serotonina, levando a uma diminuição na condutância dos canais de potássio que apresentem sua função alterada por possível influência genética. Desta forma, haveria desestabilização na condução iônica, gerando os episódios atáxicos. Esta desestabilização iônica seria revertida, em parte, através da alteração do $\mathrm{pH}$ do ambiente extracelular causada pela acetazolamida.

\section{REFERÊNCIAS}

1. Griggs RC, Nutt JG. Episodic ataxias as channelopathies. Ann Neurol 1995;37:285-287.

2. Gordon N. Episodic ataxia and channelopathies. Brain Dev 1998;20:9-13.

3. Vahedi K, Joutel A, Van Bogaert P, et al. A gene for hereditary paroxysmal cerebellar ataxia maps to chromosome 19p. Ann Neurol 1995;37:289-293.

4. Yue Q, Jen JC, Thwe MM, Nelson SF, Baloh RW. De novo mutation in CACNA1A caused acetazolamide-responsive episodic ataxia. Am J Med Genet 1998;77:298-301.

5. Braham J, Siegal T, Sadeh M. Periodic ataxia: an unusual non-familial variation with paroxysmal EEG features. J Neurol 1982;227:55-59.

6. Verlooy P, Velis DN. Non-familial periodic ataxia responding to acetazolamide. Clin Neurol Neurosurg 1985;87:35-37.

7. Lou JS, Goldfarb L, McShane L, Gatev P, Hallett M. Use of buspirone for treatment of cerebellar ataxia: an open-label study. Arch Neurol 1995;52:982-988.

8. Friedman JH. Machado-Joseph disease/spinocerebellar ataxia 3 responsive to buspirone. Mov Disord 1997;12:613-614.

9. Rohr A, Eichler K, Hafezi-Moghadam N. Citalopram, a selective serotonin reuptake inhibitor, improves symptons of Friedreich's ataxia. Pharmacopsychiatry 1999;32:113-114.

10. Bear MF, Connors BW, Paradiso MA. Neuroscience: exploring the brain. Baltimore:Williams \& Wilkins, 1996:135-136.

11. Nicoll RA. Introdução à farmacologia das drogas do SNC. In Katzung BG (ed). Farmacologia básica e clínica. $5^{\circ}$ Ed, Rio de Janeiro: Guanabara Koogan, 1994:227.

12. Johnsen JA, Miller VT. Tobacco intolerance in multiple system atrophy. Neurology 1986;36:986-988.

13. Houi $\mathrm{K}, \mathrm{Oka \textrm {H }}$, Mochio $\mathrm{S}$. The effects of nicotine on a patient with spinocerebellar degeneration whose symptoms temporarily exacerbated by cigarette smoking (Abstr). Rinsho Shinkeigaku 1993;33:774-776.

14. Benwell ME, Balfour DJ. The effects of nicotine administration on 5-HT uptake and biosynthesis in rat brain. Eur $\mathbf{J}$ Pharmacol 1982;84:71-77.

15. Takada Y, Ihara H, Urano T, Takada A. Changes in blood and plasma serotonergic measurements in rats: effect of nicotine and/or exposure to different stresses. Thromb Res 1995;80:307-316.

16. Takada Y, Urano T, Ihara H, Takada A. Changes in the central and peripheral serotonergic system in rats exposed to waterimmersion restrained stress and nicotine administration. Neurosci Res 1995;23:305-311.

17. Griggs RC, Moxley RT, Lafrance RA, McQuillen J. Hereditary paroxysmal ataxia: response to acetazolamide. Neurology 1978;12:1259-1264.

18. Bain PG, O'Brien MD, Keevil SF, Porter DA. Familial periodic cerebellar ataxia: a problem of cerebellar intracellular $\mathrm{pH}$ homeostasis. Ann Neurol 1992;31:147-154. 